\title{
Development of speech sounds and syllable structure of words in Zulu-speaking children
}

\author{
Yugeshiree Naidoo, Anita van der Merwe*, Emily Groenewald and Elsie Naudé \\ Department of Communication Pathology, University of Pretoria, Pretoria 0002, South Africa \\ *Corresponding author, e-mail: anita.vandermerwe@up.ac.za
}

\begin{abstract}
This study investigated development of speech sounds and syllable structure of words in 18 Zulu-speaking children between the ages of 3.0 and 6.2. A 100-word spontaneous conversational sample was elicited from each subject. All samples were transcribed phonetically by a stringent transcription procedure. The UNIBET was used to code the transcription into computer recognisablesymbols. The Phonetic Calculator Program (PCP) analysed the samples in terms of speech sound inventory, syllable structure of words and the frequency of occurrence of speech sounds and syllable structures. The data were processed to allow for the comparison of the findings at three age levels, namely 3.0-4.0 (Group 1), 4.1-5.1 (Group 2) and 5.2-6.2 (Group 3). There was developmental progression, but much speech and syllable structure development seems to occur before the age of 3.0. However, the speech sound inventory and syllable structure inventory were incomplete by the age of 6.2. The nasals, plosives, approximants and fricatives were found to develop earlier than the affricates, clicks and prenasalised consonant sounds. The shorter syllable strings were found to develop earlier than the longer syllable strings. The phonetically more complex sounds and syllable structures were produced more frequently by the older subjects, demonstrating developmental progression. The findings have important clinical implications for the speech-language therapist.
\end{abstract}

\section{Introduction}

South Africans live in a multilingual and multicultural society and this poses a challenge on many different fronts. Speech-language therapists in South Africa are faced with the challenge of providing an equitable and appropriate service to a linguistically- and culturally-diverse population. There are numerous impediments to service delivery, one of the most significant being the lack of documented linguistically- appropriate norms of speech development for all the languages spoken in South Africa, aside from English (Kunene, 1999). Languages differ in terms of the size and content of speech sound inventory, the phonotactic constraints of the language, the syllable structures of words and the phonetic complexity of the sounds. The norms of one language can thus not be applied to other languages. Language-specific normative data are critical in speech-language therapy, as they facilitate the differentiation between true speech-language pathology and speechlanguage difference. In addition to normative data assisting in identifying the presence or

absence of a problem and making early and appropriate referrals possible, it facilitates the identification of goals and procedures for treatment, as these are usually based on developmental processes (Creaghead et al., 1989). There are undoubtedly precautions in the use of normative data on speech sound development, as individual differences must be recognised, and no child should be expected to perform on target at every prescribed age interval. These norms should therefore not be used as a measurement tool. This does not detract from the fact that normative data on speech sound development, when used advisedly, is a useful guide in the identification and treatment of articulatory and phonological disorders. Fundudis et al. (1979) found that children with unresolved speech disorders by the ages of six or seven often had persisting literacy problems. Thus, the prevalence of articulatory disorders, as well as the long-term impact of these disorders, validates research into this sphere. 


\section{Speech sound development}

Numerous authors have attempted to define articulation. McWilliams et al. (1984) in their definition highlighted the interrelationship between articulation and language, which is emphasised by most authors on this subject. McWilliams et al. (1984) described articulation at a phonetic level as being the movement of the articulators in modifying the air stream in a co-ordinated fashion, and articulation at a phonological level as the patterning of speech sounds and the phonemic contrasts that are used to express meaning. Development over time occurs for all children in both aspects; that is, both motor development and linguistic development.

There are some broad universals in the order of speech sound acquisition. It is important to note that uniformity in the consonant inventory of a range of languages does not refer to the detailed phonology of an individual child (Vihman, 1993). Bearing this in mind, consider that Jakobson (1968) found that the first consonants acquired are usually $/ \mathrm{p} /$ or $/ \mathrm{m} /$, followed by $/ \mathrm{t} /$ and later $/ \mathrm{k} /$. He added that the first vowel to develop is /a/ followed by /i/ or $/ \mathrm{u} /$. The /a/ referred to here is fronted almost to the position of /q/. Jakobson has been criticised in some instances for his prescriptiveness. Some theorists are of the opinion that there is too much variation in terms of languages, individual variation between children as well as variability within a child's speech at any age level to form any firm and specific conclusions regarding a universal order of speech sound development. However, there has been substantial agreement from numerous authors (Costello, 1984; Hoffman et al., 1989; Crary, 1993; Hawkins, 1995) regarding elements of Jakobson's theories. There is agreement that vowels are the first sounds to develop, followed by nasals, then glides, then stops, then fricatives and lastly affricates. As regards the vowels, front vowels develop first and all vowels are usually acquired by the age of 2.6.

Some speech sounds and syllable sequences are common to many languages, and these sounds and sequences are labelled as more likely or natural than others (Vihman, 1993). Sounds that are rare, or not common in many languages, tend to develop later. The same would apply to sounds that are complex or more demanding of the articulatory mechanism, for example clicks (Bernhardt \& Stemberger, 1998). According to Hawkins (1995) and Bernhardt and Stemberger (1998) the more frequently produced or more common a speech sound is in a specific language, the earlier it is mastered. These cross-linguistic frequency effects have been reported by Pye et al. (cited by Bernhardt \& Stemberger, 1998). There are undoubtedly rules of articulation that are universal, partly because these rules are confined by the perceptual limitation of human beings and the physiology of the articulatory mechanism and central nervous system at a given age (Vihman, 1996). However, each language has a specific set of sounds and permissible arrangement of these sounds in words. Rules which are unique to a specific language regulate processes for adding, deleting or changing sounds.

\section{Syllable structure development}

If speech is to be analysed, the unbroken stream of movement has to be 'split up' into units. The syllable is one such unit. Syllables are intuitively recognized by most people (Abercrombie, 1967). Jakobson (1968) postulated a universal order of acquisition of the syllable structure of words. He indicated that the first syllable structure (of words) to develop was consonant vowel (CV) or CV reduplicated, followed by $\mathrm{CVC}$ and $\mathrm{CVCV}$ (where the second consonant-vowel combination is different from the first).

According to Bernhardt and Stemberger (1998), there is a tendency for the less complex or more natural syllable structures to occur frequently in a language, and to be mastered earlier. In other words, there is a correlation between the frequency of a syllable structure in a specific language and how early that structure is acquired. According to Stockwell and Macaulay (1972) there are natural rules for preferred syllable structures. Stockwell and Macaulay (1972) postulate that open syllable structures, for example CVCV, are preferred to closed structures, for example CVC. Preferred syllable structures also do not place vowels next to each other, and VCV would consequently be more natural than VV. Furthermore a vowel installed between two consonants is a more natural syllable structure than two consonants next to each other.

Languages have varying syllable 
inventories. Some languages consist of only CV syllables while others have extensive inventories including $\mathrm{CV}, \mathrm{CVC}, \mathrm{CCVC}$ and CVCC (Levelt et al., 1999). This fact again serves to highlight the inappropriacy of generalising from one language to another. No studies to date have been found in the literature describing Zulu syllable structure development.

\section{Previous research on development of Zulu speech sounds and syllable structure of words}

The undergraduate research projects of Urquhart (1967), John (1988) and Kunene (1999) have contributed to the limited pool of data on Zulu speech development. However, the appropriacy of generalising their findings to the population is limited by small sample sizes and methodological problems. Urquhart (1967) investigated the speech acquisition of Zuluspeaking children. The significant findings of her study include that nasals were the earliest to develop, followed by resonants, fricatives and clicks. The limitations of the study lie in the fact that the Zulu phonetic inventory utilised is outdated and not in line with current developments in Zulu phonetics and linguistics. In addition, each speech sound was only assessed in one word position, either wordinitially or word-finally, and each speech sound was elicited once in a picture-naming task. Both these factors prevented identification of variations in production. Furthermore, little attention was paid to limiting variables in subject selection and sample selection. John (1988) conducted a study aimed at describing the phonological processes present in the speech of Zulu-speaking children. This study's major findings were that weak syllable deletion, fronting, reversal of liquids, context-sensitive voicing and stopping are processes prevalent in the speech of Zulu-speaking children between three and five years of age. The most common process was the fronting of alveolar and dental clicks. The finding that clicks are the last sound class to develop is supported by the findings of Urquhart (1967). John (1988) also utilised single words as the sample, but a greater attempt was made to allow for more than one production of each speech sound. Of concern was that certain consonant sounds were left out of the sample, as they did not occur frequently in Zulu and more importantly, that phonological processes identified in EuroAmerican languages were being applied to a language of which little was known. Moreover, insufficient attention was paid to controlling the confounding variables, which could have tainted the results, and this influenced the reliability and generalisability of the findings.

The most recent study, that of Kunene (1999), investigated speech acquisition in Zuluspeaking children. The findings were that stops, liquids, glides, nasals and fricatives develop earlier than clicks and affricates. This was similar to the findings of Urquhart (1967). Surprisingly, Kunene (1999) found that all the Zulu speech sounds were mastered by the majority of her sample as early as age three, and only the speech sound $/ \mathrm{k} /$ was still marginal. By the age of four, all of the sounds had been mastered (Kunene, 1999). However, the sample consisted of sounds produced in isolated words, and thus no comment could be made on the manner in which these sounds were produced at conversational level. In addition, it was unclear whether all the words were elicited spontaneously, or whether some were elicited by imitation. This highlights the difficulty of comparing the findings of different studies, as researchers have different operational definitions, and different sampling and analysis techniques. The literature search did not reveal any studies regarding the syllable structures used by Zulu-speaking children, or the frequency of sound and syllable production in Zulu-speaking children.

\section{General information on Zulu}

Zulu is recognised as one of the 11 official languages in South Africa. It is one of the socalled 'Nguni' group of languages, which also include Xhosa, Swathi and Ndebele (Poulos \& Bosche, 1997). Zulu was the language of focus in the present study, firstly because of the size of the Zulu-speaking population and secondly due to the scarcity of research involving Zulu subjects (Rennison \& Suzman, 2000). According to Census 1996 (Statistics South Africa, 2000), Zulu is the most commonly spoken language in South Africa and is spoken by $22.9 \%$ of the South African population.

In the absence of relevant norms or normative indications, South African speechlanguage therapists tend to inappropriately use English norms on Zulu-speaking children. 
However, there are considerable differences between English and Zulu, namely:

- The phonetic inventory of Zulu is much larger than that of English. English has a phonetic inventory of approximately 24 consonants and 14 vowels (Weiss et al., 1987) while Zulu has 59 consonant sounds, according to the consonant chart utilised in the present study (Naidoo, 2003), and seven vowels.

- Zulu has a unique click structure that does not occur in English (Cope, 1983).

- Zulu has no consonant clusters (Taljaard \& Snyman, 1993), while English does allow for consonant clusters (Creaghead et al., 1989).

- All Zulu syllables are open (Poulos \& Msimang, 1998), while in English both open and closed syllables occur (Cope, 1983).

- Zulu has a number of aspirated sounds differentiating meaning, and this is not a feature of English (Van Rooy \& Grijzenhout, 2000).

- Prenasalisation is a common feature of Zulu, but not of English (Cope, 1983).

This list of differences is by no means exhaustive, but serves to highlight some of the important differences between Zulu and English.

\section{Phonetic features of Zulu}

Research and debate regarding the phonetic structure of Zulu is vigorous (R Bailey, pers. comm.). Various phoneticians, including Bailey (pers. comm.), Cope (1983), Doke (1967), Lanham (1960), Poulos and Bosche (1997), Poulos and Msimang (1998), Taljaard and Snyman (1993) and Westerman and Ward (1990), have worked in this field. The following outline of the sound structure of Zulu, as accepted for the purposes of the present study, is based on the current researcher's comparison and integration of various descriptions published since 1960.

\section{Consonant sounds}

In Zulu, there are two types of consonant sounds, namely plain consonants and clicks. According to Taljaard and Snyman (1993), the plain consonants consist of plosives, affricates, fricatives, approximants, nasals and two consonant sounds that are unique to Zulu, which are the implosive $/ \mathrm{b} /$ and the partiallyvoiced $/ \mathrm{k} 3 /$. There is also a syllabic $/ \mathrm{m} /$ which results from a low level or superficial reduction of $/ \mathrm{mu} /$ to $/ \mathrm{m} /$ (R Bailey, pers. comm.). The $/ \mathrm{r} /$ sound is not an integral part of Zulu phonology, has a low frequency of occurrence and occurs only in words adopted or 'borrowed' from other languages, for example English and Afrikaans.

\section{Clicks}

According to Westerman and Ward (1990), one-seventh of all Zulu words have a click. There are three click positions, namely dental, palatal and alveolateral. There are voiceless clicks, for example /i!a!a/, aspirated clicks, for example /u! h $^{\text {!ho }} !^{\mathrm{h}} \mathrm{o} /$, voiced clicks, for example /isi!gok3o/, nasalised clicks, for example /ia!indi/, and prenasalised voiced clicks, for example /ia!g9nd $9 /$.

\section{Affricates}

According to Poulos and Msimang (1998), affricates are a more complex type of stop. In the production of affricates, there is air pressure build-up behind the closure, which is released slightly, causing audible friction. Thus, the initial element of the sound has a sharp plosive character, and this is followed by an element of audible friction. Examples of affricates in Zulu include $/ \mathrm{ts} /$ and $/ \mathrm{k} /$, and prenasalised affricates include / $/ \mathrm{M} \varphi /$ and /at $\%$.

\section{Aspiration}

According to Lephallo (1990), aspiration is a common feature of Zulu, and consists of sounds that are produced with 'an extra puff of air' or an audible air current that forces its way through the vocal folds. Aspiration in Zulu causes phonemes to be contrasted in terms of meaning. In phonetic transcription, the aspiration is depicted by a small raised $/ \mathrm{h} /$, following the aspirated sound, for example $/ \mathrm{p}^{\mathrm{h}} /$.

\section{Breathy voice}

This type of phonation is found in Zulu, Shona and Hindi, and is described as a situation where the vocal folds are relaxed yet vibrating, combined with a whisper through the posterior portion of the folds (Ball \& Rahilly, 1999). The feature of breathy voice is to be distinguished from aspiration. Breathy voice does not differentiate lexical meaning, and was thus not recorded in the present study.

Prenasalisation 
Prenasalisation refers to the phenomenon where there is a momentary escape of air through the nasal cavity, before the raising of the velum and the build-up of air pressure, which is released at the lips. The momentary passage of air through the nasal cavity constitutes the prenasalisation, for example ladz, adL, nts, M $\varphi f /$. The prenasalisation of a speech sound is not recognised as a separate entity, but rather as a feature of the speech sound (R Bailey, pers. comm.). In the current study, each of these prenasalised speech sounds was counted individually. In the phonetic transcription, all the prenasalised sounds are preceded by one of the following symbols: /M, a, n, m/.

\section{Syllabic /m/}

Syllabic $/ \mathrm{m} /$ describes the bilabial nasal $/ \mathrm{m} /$ preceding the $/ \mathrm{u} /$, which is followed by either a bilabial or a labiodental sound, becoming syllabic by the vowel being discarded. This occurs only in bisyllabic or polysyllabic stems, for example, umufundisi becoming /umpfundisi/ (Lephallo, 1990).

\section{Consonant clusters}

\section{According to Doke (1967) and Ziervogel} (1967), consonant plus $/ \mathrm{w} /$ and nasal consonant clusters are permitted in Zulu. However, in the last 20 years, the view on Zulu 'consonant clusters' has changed. Phoneticians agree that there are no consonant clusters in Zulu, but that the sounds function as individual phonemes. Currently, phoneticians recognise that each instance of labialisation, palatalisation, aspiration and prenasalisation that occurs in Zulu is a phonetic feature of the specific consonant and does not create an independent phoneme. Therefore the term 'consonant cluster' is not appropriate (Lanham, 1960; Taljaard \& Snyman, 1993; Poulos \& Msimang, 1998). Furthermore, these consonant sequences behave phonologically as a single unit (Burton \& Blumstein, 1992). An example of this phenomenon is the speech sound $/ \mathrm{mp} /$. This, in terms of Zulu, is referred to as a prenasalised consonant sound. It should be noted that in the normal orthography, a single consonant sound may be represented by two or three different letters, for example /ts; kl; tsh; sh; mf; nd; ndl; nkc; gq; nhl/. In addition, in the phonetic transcription, a single consonant sound may be represented by two or three symbols, for example, /k; a!, adL/. According to Cope (1983), the phonotactic rules of Zulu oppose consonant clusters, so that even borrowed words have vowels installed between two or more consonants.

\section{Vowels}

According to Westerman and Ward (1990), Zulu has a remarkably simple vowel sound inventory. There are five Zulu vowel sounds, indicated by the symbols $/ a, e, i, o, u /$. The front vowels are /i, e/, the central vowel is /a/ and the back vowels are /u, o/. However the /e/ and /o/ have two values, /e/ or $/ 2 /$, and $/ 0 /$ or $/ 9 /$, which do not affect meaning and are used according to vowel harmony, the term used by Poulos and Bosche (1997). In the present study, the total number of vowel sounds was documented as seven, in order to take the additional /2/ and / $/ 9 /$ into account. In Zulu, the length of the vowel does not distinguish meaning, and there are no diphthongs (Taljaard \& Snyman, 1993).

\section{Syllable structure of words}

The syllable structure of Zulu words is simple compared to that of English. All syllables are open-ended, which means that they end in a vowel or a syllabic $/ \mathrm{m} /$. All Zulu words comprise one to nine syllables of the V, CV, VCV type (Lanham, 1960; Doke, 1967; Poulos \& Bosche, 1997; Poulos \& Msimang, 1998).

\section{The purpose of the study}

The cost, time and logistics involved in embarking upon a normative study are extensive. The present study was undertaken to determine normative indications. The findings would be relevant and useful in clinical practice, as well as in providing the groundwork from which further research can emerge. The aims of the study were:

- To determine the speech sound inventory of Zulu-speaking children between the ages of 3 years, 0 months (3.0) and 6 years, 2 months (6.2)

- To determine the frequency of occurrence of speech sounds, as a function of age

- To determine the syllable structure of words produced by Zulu-speaking children as a function of age 
- To determine the frequency of occurrence of the syllable structure of words, as a function of age

At present, there is no account of Zulu speech development in the literature that includes normal Zulu-speaking children between the ages of three and six and that is based on samples of natural continuous speech. The purpose of this study is to create a database for the documentation of normative indicators of speech sound and syllable development in Zulu-speaking children, based on samples of continuous speech.

\section{Method}

\section{Subjects}

Eighteen normal-speaking Zulu children between the ages of 3.0 and 6.2 years were selected as subjects. All the children had to have Zulu as their first language, and have Zulu spoken in their homes and school. Six subjects were selected in each of the following age groups: 3.0 to 4.0 (Group 1), 4.1 to 5.1 (Group 2 ) and 5.2 to 6.2 (Group 3). These age groups were selected because of the extent of speech sound development that occurs between the ages of 3.0 and 6.2 (Irwin \& Wong, 1983; Costello, 1984; Hoffman, 1986; Weiss et al., 1987). A lower age limit of 3.0 was set to ensure that the required continuous speech sample of 100 words could be achieved. By age three, children are usually able to offer more satisfactory co-operation than younger children, which enhances the reliability of results. By the age of three, children are able to construct sentences and speak on a variety of topics, thus allowing for an extensive sample of conversational speech. An upper age limit of 6.2 was selected, because by the age of 6.2 most of the speech sound development will have occurred, according to the English norms of speech sound development (Hawkins, 1995). Gender representation was balanced to increase the representative nature of the sample.

Subjects had to adhere to a number of criteria to be representative of the target group and to be classified as 'normal' in terms of general developmental aspects. These included requirements such as no indication of cognitive impairment, no indication of articulation or language problems, normal hearing and vision, normal structure and function of oral anatomical structures and a normally-maturing body with no anatomical abnormalities. The subjects had to be free of any paresis, paralysis, abnormal reflexes and involuntary movements of the body, chronic illness or prolonged hospitalisation. Further, all the subjects had to share a similar socioeconomic status. For this reason, all the children were selected from the same school, the population of which consisted of children from middle- to low-income families. Only children with regular school attendance were selected as the school was considered a stimulating environment, where the children met with good speech models. For each of the criteria, appropriate control measures including a checklist for the teachers, a questionnaire for the parents, hearing screenings and oral examinations were used to ensure that the subjects met all the requirements.

\section{Research assistant}

A research assistant was employed, as the researcher is not a first-language Zulu speaker and would thus have had difficulty engaging the subjects in spontaneous conversation. The role of the research assistant was to engage the subjects in conversation and thus elicit the sample of continuous speech. The research assistant was a first-language Zulu speaker, from the same cultural background as the children. She was patient, caring and adept at working with children. Furthermore, the research assistant was trained and experienced in speech elicitation techniques.

\section{Research design}

Survey research was used, which allowed the researcher to describe the natural speech sound and syllable production of a specified group of Zulu-speaking children in a natural communicative setting. An important characteristic of this type of research is that the researcher does not attempt to manipulate variables but simply describes what exists (Mouton \& Marais, 1990). The survey design demanded a carefully-chosen population, careful organisation, minimisation of bias and systematic presentation of the data (Leedy, 1997). The data obtained was of a quantitative nature and statistical means were used to extract meaning and interpret the findings.

Stratified random sampling was utilised, 
which dictated that each unit within the target population needed to be identified, in order to ensure that each child had a positive chance of being part of the sample. In order to comply with this, a strict pre-selection procedure was embarked upon. The categories were specified as the required age groups of the subjects. Within each category, the male and female subjects were separated. Equal allocation in terms of gender, within each age group, was done. Within each category, random sampling was done, to prevent human bias.

\section{Ethical considerations}

Approval was obtained from the ethics committee of the Faculty of Humanities, University of Pretoria. Permission was obtained from the school to conduct the study, and permission was obtained from the parents and caregivers to utilise the data for research.

\section{Material}

A sample of continuous speech

A sample of continuous speech refers to a sample obtained in a natural communicative, conversational setting. For the purposes of the present study, a sample of continuous speech was considered most suitable to be representative of the range and distribution of sounds in the subject's speech sound inventory. The validity, stability and utility of conversational speech samples for research in normal or disordered speech has been supported in a number of studies (Shriberg \& Widder, 1990; Shriberg \& Lof, 1991; Morrison \& Shriberg, 1992). In addition, a sample of continuous speech was the only valid means of determining the frequency of occurrence of specific sounds and syllable structures in spontaneous speech. According to Creaghead et al. (1989), a sample of continuous conversational speech reflects the child's habitual speech production in actual communicative settings, and is thus the only true measure of articulatory proficiency. The representivity of a continuous speech sample is dependent on the sample being large enough and sufficiently varied in content to ensure that a given sound occurs more than once in each word position. Grunwell (1982) recommends a 100-word sample at a minimum. A 100-word sample was selected as adequate for the purposes of the present study. A hundred words were obtained from 18 children. In other words 1800 words served as data in this study. The sample size was feasible to elicit from young subjects.

The validity of elicited speech data has been questioned by various authors, including Grunwell (1982), Smit (1986) and Creaghead et al. (1989). The main concern is that elicited speech, gained mainly by picture-naming tasks or by imitation, is not representative of a child's spontaneous conversational speech. According to Smit (1986), children's imitative utterances have been found to be closer to the adult target than their normal non-imitative utterances, and this brings the validity of the findings into question. The benefit of the elicited sample is that a sample of every speech sound can be guaranteed, whereas in a continuous speech sample, the sounds produced by the child cannot be predetermined.

\section{Speech elicitation stimuli}

Speech elicitation stimuli needed to be culturally valid and relevant. Items selected for use in the data collection included a doll and dolls' clothing, a model house and furniture, a tea set, a low-tech car racing set, cooking utensils and dishes, an animal picture book, action pictures depicting routine activities and plastic food models. It is important to note that these items served as stimuli and not test material, and therefore did not require validation. The stimuli were required to encourage rapport, to allow for variation of the subject matter, to serve as topics of conversation and to encourage play and interaction between the research assistant and the subject.

\section{Zulu consonant chart}

The speech sound inventory of Zulu was of relevance to the present study in accurately transcribing the speech samples as well as in comparing the subjects' sound production. At present there is no standard consensual consonant chart for Zulu. There is controversy regarding the size of the inventory, the most appropriate symbols to use, the description of the sounds, the place of articulation, manner of articulation, the air stream and the representation of prenasalised consonant sounds. In addition, some of the consonant charts available in the literature were too 
descriptive or detailed for the purpose of the present research. The Zulu consonant chart utilised in the present study (see Appendix A) was based on the consonant charts presented in Poulos and Msimang (1998), Westerman and Ward (1990) and the International Phonetic Alphabet (IPA). An attempt was made to utilise the IPA classification for maximal recognition internationally. In the current study, all the prenasalised consonants were regarded as single sounds, and not consonant clusters or nasal compounds. The Zulu consonant chart was validated by two phoneticians ( $R$ Bailey pers. comm.; HEC Tesner, pers. comm.).

\section{Apparatus}

A Madsen Electronics portable audiometer was used for the hearing screening. The speech samples were recorded on a high-quality Sony tape recorder with an external lapel microphone. High quality TDK cassettes were used in the recordings.

For the analysis and processing of data, Microsoft Excel and the Phonetic Calculator Program (PCP) designed by Charles Musto was used. The PCP is a user-friendly, personalcomputer compatible, windows-based software program which can be used for the analysis and quantification of the sound structure of any language (Groenewald \& Musto, 1999).

\section{Data collection and recording procedure}

The recordings were made in a quiet room on the school premises. All potential distractors were removed, proper lighting was ensured and a child-sized table and chairs were utilised. The room was arranged so that the research assistant and the subject sat together. The researcher sat three metres away from them. A clip-on microphone was secured to the child's clothing, $10-15 \mathrm{~cm}$ from the child's mouth, for a clear recording with minimal distortion ( $E$ Groenewald, pers. comm.). The researcher was in the room to monitor the input level of the recording, to advise the research assistant if difficulties arose, to ensure that the speech sample size was achieved, and to record relevant contextual cues.

The research assistant established rapport with the child by engaging in casual conversation, in the context of play. She was advised to open an avenue of discussion, and then follow the child's lead, as well as to frequently change the activity or topic. Topics introduced by the child were accepted and encouraged. In addition to conversation about the toys and material, continuous speech was elicited by story- telling, discussion of interests and experiences. Each activity or topic was maintained for three to five minutes, to ensure continued interest and to facilitate the elicitation of a variety of different utterances. The duration of the session was approximately 35 minutes per child.

\section{Data analysis procedure}

Perceptual analysis was the most effective and practical approach for the analysis of the speech samples. The expertise of a phonetician was required to guide the researcher and validate the transcription. The phonetician who assisted the researcher had postgraduate training in general phonetics and linguistics, possessed expert knowledge on Zulu phonetics and also had teaching and research experience. The researcher had been working with Zulu speakers in a clinical setting for a number of years and had a good perceptual knowledge of Zulu.

The phonetician and the researcher, as part of the training, did the transcription of one randomly-selected sample together. The researcher then perceptually transcribed each speech sound in the remaining 17 recorded samples. Every word uttered by the subject was phonetically transcribed, except for words that were inaudible to the researcher due to fluctuations in the quality of the recording. Where the child habitually used the same word, for example, continually answering 'yes' to many questions, this word was not recorded more than three times. This was done because the 100-word sample was relatively small, and a variety of utterances, depicting the range and distribution of the child's speech sound inventory and syllable inventory, had to be gained. Only the consonant sounds and vowel sounds that were correctly produced, as compared to the typical realisation of the sound by adult Zulu speakers, were documented. Sounds that were distorted were omitted.

The validity of the transcriptions was checked by the phonetician. Two hundred randomly-chosen words were checked. Two error types were found: the misrepresentation 
of the allophonic vowels /e/ for $/ 2 /$, and $/ 0 /$ for $\mathrm{I} /$ /, and the misrepresentation of the voiceless plosive $/ \mathrm{k} /$ as the partially-voiced plosive $/ \mathrm{k} 3 /$. All the transcriptions were rechecked, and the necessary corrections were made.

For the conversion of the manuallytranscribed speech sounds to computer keyboard-compatible symbols, the UNIBET system was used. The UNIBET system is the phonemic alphabet of the PHONASCII system, a system developed for the computer coding of phonetic symbols. According to Allen (1988), the UNIBET system is internationally recognised, is based on the IPA, utilises the keys of the standard computer keyboard, is inexpensive and does not require additional equipment or software. The UNIBET symbols are based on English dialects, and have equivalent symbols for the IPA. However, it makes provision for the addition of non-English speech sounds by devising additional symbols. Where there were no appropriate symbols for specific Zulu speech sounds, for example /nt, $\mathrm{k} \ell$, the researcher added additional symbols. Furthermore, the researcher identified additional UNIBET symbols for each of the prenasalised sounds. Once each transcribed sound had an equivalent UNIBET symbol, the researcher manually translated each speech sound of the 18 samples to the equivalent UNIBET symbol. The 18 samples were entered into Microsoft Word as separate files, utilising the standard computer keyboard. The symbols that were additionally created were added to the standard list of symbols to ensure that the $\mathrm{PCP}$ recognised all these. All 18 files were entered into the input section of the PCP.

The word count function of the PCP presented the number of words transcribed in each file, identified each symbol as a vowel (V) or a consonant $(C)$, counted the total number of vowels and consonants in each file and determined the percentage of the vowels and consonants in each file. The frequency of occurrence of the vowels and consonants for each subject was necessary in order to calculate the cumulative totals for each age group. The PCP results showed the frequency of occurrence of each sound as it occurred in each file. These frequencies of occurrence were calculated as percentages of the total number of sounds produced by each subject.

The PCP software program furthermore identified the specific structure of each word utterance, in terms of sequences of consonants and vowels (e.g. CV, VC and CVCV). The PCP counted the frequency of occurrence of different syllable structures produced by each subject and also the frequency of occurrence of each structure as percentages of the total word count, for each subject.

\section{Data processing}

The first aim was to determine the speech sound inventory of Zulu-speaking children at the ages 3.0 to $4.0,4.1$ to 5.1 and 5.2 to 6.2 . The PCP listed all the sounds in each speech sample. The researcher grouped the subjects in terms of the predetermined age groups. Within the age group, one mark was allocated to each sound, for each subject who produced the sound correctly. This was irrespective of the number of times the sound had been produced correctly in the sample, or whether the sound occurred word-initially, within-word or wordfinally. A sound was considered to be produced correctly if the subject's realisation of the sound matched the typical adult Zulu realisation of the sound. Each sound could thus be allocated a maximum of six marks, because there were six subjects in each age group. A specific speech sound was considered present in the speech sound inventory of a specific age group if the speech sound was produced correctly by at least five of the six subjects.

The second aim was to determine the frequency of occurrence of speech sounds as a function of age. The PCP analysis determined the number of times each speech sound was produced by each subject as well as the total number of consonant sounds and vowel sounds in each speech sample. In essence, the PCP provided the researcher with a simple frequency distribution of each sound, for each subject. The researcher grouped the data in terms of the three age groups. By considering the data for all the subjects in a group, a grouped frequency distribution (GFD) can be calculated and used to summarise, compare and display data (De Vos, 1998). In the present study, grouping of data was done in terms of pre-selected age groups. The number of times that each sound was produced by each subject in a specific age group and the number of consonant sounds and vowel sounds produced for each age group, was tallied. The mean 
score was derived by dividing the total number of times a specific sound had occurred in a specific age group by either the total consonant sounds for that age group or the total vowel sounds for that age group. The resulting figure was multiplied by 100 , to calculate a percentage. The mean value effectively specified the centre of gravity or balance point, and is described as the most stable and versatile measure of central tendency (De Vos, 1998).

The third aim was to determine the nature of syllable structures produced by Zuluspeaking children, as a function of age. The data generated by the PCP included a list of all the syllable structures that each subject had produced. The researcher grouped the findings into the three pre-specified age groups. A specific syllable structure was considered present if it had been produced at least once by at least five of the six subjects in the age group. A list of the different types of syllable structures was compiled for each group.

The fourth aim was to determine the frequency of occurrence of the various syllable structures, as a function of age. The PCP analysis generated a simple frequency distribution of the syllable structures used by each subject. This included for each subject, each syllable structure used, the number of times each syllable structure had been used, as well as the percentage of the total word count that each syllable structure represented. In order to facilitate comparisons between age levels, the data was grouped into the three pre- specified age levels to obtain a GFD (De Vos, 1998). The researcher added the number of times each subject in an age group had used a specific syllable structure. The total word count was 600 for each age group, because each subject had produced 100 words, and there were six subjects within each age group. From this information the mean score was calculated, to determine the average performance in each age group. This was done by dividing the total frequency of occurrence of a specific syllable structure for each age group by the total word count for that age group. This indicated the percentage of the total word count the specific syllable represented. The mean was selected as the most reliable or accurate measure of central tendency in the present research.

\section{Description of results The speech sound inventory of the three groups of Zulu-speaking children}

The results relating to this sub-aim are summarised in Table 1. As can be seen from Table 1, seven vowel sounds occurred in the speech of all three age groups, namely /a; 2; e; i; 9; o; u/. This is the complete set of vowel sounds that occur in Zulu (Doke, 1967; Cope, 1983; Poulos \& Bosche, 1997).

With regard to the consonant sounds, there were two instances of developmental progression between the ages of 3.0 and 6.2. The production of the consonant sound /nt/ occurred in Groups 2 and 3 but not in Group 1. In addition, the consonant sound /nts/ was

Table 1: Speech sound inventory for each of the three age groups, with reference to the manner of articulation

\begin{tabular}{|c|c|c|c|}
\hline Description & $3.0-4.0$ & $4.1-5.1$ & $5.2-6.2$ \\
\hline \multirow[t]{3}{*}{ Plosives } & $p t k$ k3 & $p t k$ k3 & $p t k k 3$ \\
\hline & $p^{h} t^{h} k^{h}$ & $\mathrm{p}^{\mathrm{h}} \mathrm{t}^{\mathrm{h}} \mathrm{k}^{\mathrm{h}}$ & $p^{h} t^{h} k$ \\
\hline & $\mathrm{b} \mathrm{d} \mathrm{g}$ & $\mathrm{b} \mathrm{d} \mathrm{g}$ & $\mathrm{b} \mathrm{d} \mathrm{g}$ \\
\hline \multirow[t]{3}{*}{ Fricatives } & $v z$ & $v z$ & $v z$ \\
\hline & L : & $\mathrm{L}:$ & L : \\
\hline & f S C & fs C & f S C \\
\hline Nasals & $\mathrm{m}$ a $\mathrm{n}$ & $\mathrm{m}$ a $\mathrm{n}$ & $\mathrm{m}$ a $\mathrm{n}$ \\
\hline Affricates & $\mathrm{k}$ : & & \\
\hline Approximants & I w j & I wj & I wj \\
\hline Implosive & $\mathrm{b}$ & $\mathrm{b}$ & $\mathrm{b}$ \\
\hline Prenasalised plosives & $\mathrm{mb}$ nd ak & nd nt & $\mathrm{mb} n d \mathrm{nt} a \mathrm{k}$ \\
\hline Prenasalised affricates & $\mathrm{adz} a d L$ & $\mathrm{adz}$ & adz nts \\
\hline Clicks & 1 & 1 & \\
\hline Vowels & a i 9 o e 2 u & a i 9 o e 2 u & a i 9 o e 2 u \\
\hline
\end{tabular}


produced by Group 3 only. In terms of the consonant sound inventory for Group 1, the subjects produced 32 of the possible 59 Zulu consonant sounds, which amounted to $54 \%$ of the sound inventory. In Group 2, the subjects produced 28 of the 59 possible Zulu consonant sounds, which amounted to $47 \%$ of the sound inventory. In Group 3, the subjects produced 31 of the possible 59 Zulu consonant sounds, which amounted to $52 \%$ of the speech sound inventory.

A comparison of the speech sounds produced shows that all the possible plosives in Zulu, /p, t, k, k3, $\mathrm{p}^{\mathrm{h}}, \mathrm{t}^{\mathrm{h}}, \mathrm{k}^{\mathrm{h}}, \mathrm{b}, \mathrm{d}, \mathrm{g} /$, were produced by all three groups; so too were seven of the nine possible fricatives $/ v ; z ; L ; f$; $\mathrm{s}$; ; cl. All the possible approximants /l; w; j/, three of the four possible nasals $/ \mathrm{m} ; \mathrm{n}$; a/ and two of the 16 prenasalised consonant sounds lad; adz/ were included in the speech sound inventory of all three groups. Furthermore, the implosive /b/ was included in the speech sound inventory of all three age groups. The affricate /k \& was recorded as produced by Group 1 but not Group 2 and Group 3. However, as speech is developmental in nature, and $/ \mathrm{k} /$ had been produced by Group 1, it may be anticipated that this production could also have occurred in the consonant sound inventory of Groups 2 and 3 but that the sound did not occur frequently enough to meet the criteria for inclusion. Note that the additional five affricates that occur only with prenasalisation were included as prenasalised consonant sounds and not affricates.

When the findings for Group 1 were compared to the Zulu consonant chart (Appendix A), it was evident that the following consonant sound realisations were not present: /ts; c; !; //; /h; !h; //h; dx; /g; !g;//g; H; h; a/; a!; al/; a/g; a!g; al/g; M bv; adx; mp; nt; M $\varphi f ;$ nts; atc; at $\%$ It is significant to note that of the 27 consonant sound realisations not present in the consonant sound inventory of Group 1, 14 $(52 \%)$ were clicks. There are 15 possible click consonant sounds in Zulu, including the three prenasalised clicks, and Group 1 had one included in its inventory, namely, IX. Of the 27 consonant sound realisations not present in the consonant sound inventory of Group 1, eight $(30 \%)$ were prenasalised consonant sounds (prenasalised plosives, prenasalised affricates and prenasalised fricatives), namely $/ \mathrm{M}$ bv, $\mathrm{adx}, \mathrm{mp}, \mathrm{nt}, \mathrm{M} \varphi \mathrm{f}, \mathrm{nts}$, atc, at $\%$. The rest of the consonant sounds lacking in the inventory of Group 1 were three affricates /ts, tc, $\mathrm{dx} /$, and two fricatives / $\mathrm{H}, \mathrm{h} /$.

When the sound inventory of Group 2 was compared to the Zulu consonant chart (Appendix A), it was evident that the following consonant sounds had not been realised: /ts; tc; k; !; //; /h; !h; //h; dx;/g; !g;//g; H; h; n; a/; a!; al/; mb; a/g; a!g; al/g; adL; adx; mp; ak; M $\varphi f ;$ M bv; nts; atc; at $\%$ Of the 31 consonant sounds not present in the inventory of Group 2, 17 (55\%) were found to be clicks. In Group 2, as in Group 1, / X was the only click produced. Of the 31 consonant sounds not in the consonant sound inventory of Group 2, 10 (32\%) were prenasalised consonant sounds, namely $/ \mathrm{mb}$, M bv, adx, adL, mp, ak, M $\varphi f$, ats, atc, at $\%$. The remaining consonant sounds not in the inventory of Group 2 were four affricates /ts, tc, $\mathrm{k}$; $\mathrm{dx} /$ and two fricatives, /H, h/. However, as indicated before, it is highly likely that $/ \mathrm{k} /$ is in the consonant inventory of all three groups.

The comparison of the consonant sound inventory of Group 3 to the Zulu consonant chart (Appendix A) indicated that the following consonant sounds were not produced /ts; tc; k: ;/; !; //; /h; !h;//h; dx;/g; !g;//g; H; h; a/; a!; a//; a/g; a!g; a//g; M bv; adx; adL; mp; M $\varphi f ;$ atc; at . On inspection of the results, it was found that of the 28 consonant sounds not produced by Group 3, $18(64 \%)$ were clicks. No clicks were produced by Group 3, unlike Group 1 and Group 2, which both had the click /X in their consonant sound inventory. However, as indicated previously, because speech is developmental in nature and the sound / $X$ had been produced in the younger age groups, it is highly likely that it would also occur in Group 3. The same would apply to /n, mb, ak/ which was evident in Group 1 and Group 3 but not in Group 2, and /adlx/ which occurred in Group 1 but not in Group 2 and Group 3. Of the 28 consonant sounds lacking in the consonant sound inventory of Group 3, seven (25\%) were prenasalised consonant sounds, namely $/ \mathrm{M}$ bv, adx, adL, mp, M $\varphi f$, atc, at $\%$. Aside from the clicks and the prenasalised consonant sounds, also excluded from the consonant sound inventory of Group 3 were four affricates /ts, tc, $\mathrm{k}$; $\mathrm{dx} /$ and two fricatives $/ \mathrm{H}, \mathrm{h} /$. 
The frequency of speech sound production as a function of age

The results with regard to the frequency of vowel sound production (see Table 2) indicate that the order of frequency of vowel production was the same across all three age groups. In all three groups, /a/ was the most frequentlyoccurring vowel, followed consecutively by $/ \mathrm{i}, \mathrm{u}$, $2,9, \mathrm{e} / \mathrm{and} / \mathrm{o} /$. The vowels were intermingled with a few consonant sounds, but the order was constant.

In general, the results revealed that all three groups shared the same four most frequentlyproduced consonant sounds, although in differing orders, for each group. These top four consonant sounds were /l, n, m, s/. In Table 2, the frequency of speech sound production in Group 1 shows that /a/ features as the most frequently-produced speech sound (19.43\%). In fact, the top four most frequently-produced speech sounds were found to be the vowels (a; $\mathrm{i} ; \mathrm{u} ; \mathrm{2}$ ). The most frequently-produced consonant sound was found to be the approximant $/ / /(5.0 \%)$, and the least frequentlyproduced consonant sound was found to be the voiceless fricative $/ \mathrm{h} /(0.03 \%)$. Interestingly, the consonant sounds more frequently produced tended to be mainly approximants, nasals, fricatives and plosives. However, those produced less frequently, with a mean frequency of less than $0.30 \%$, tended to be the affricates, clicks and the prenasalised consonant sounds. The exceptions were the voiceless fricative $/ \mathrm{h} /(0.03 \%)$, the voiced fricative $/ \mathrm{H} /(0.14 \%)$ and the plosive $/ \mathrm{p} /$ $(0.28 \%)$, which also occurred lower down the order.

\section{The syllable structures used by Zulu- speaking children as a function of age}

It was found that all three groups were capable of producing one to five syllable words of the CV and VC type (see Table 3). Group 1 and Group 2 did not produce six or seven syllable words, for example CVCVCVCVCVCV, VCVCVCVCVCV or VCVCVCVCVCVCV. While Group 3 had one of the six-syllable word structures in its syllable inventory, seven and more syllable structures were not included in the inventory. Words consisting of $\mathrm{CV}$ were not documented as present in any of the three age groups, as these words had not been produced by five or more of the subjects in each age group. CV was produced by four subjects in Group 1 and three subjects each in Group 2 and Group 3.

\section{The frequency of syllable structure production as a function of age}

The findings of the frequency analysis for each age group are depicted in Figures 1, 2 and 3. These figures display the frequency of occurrence of syllable structures of words as well as the mean frequency percentages. The results indicated that the most frequentlyproduced syllable structure in Group 1 and Group 3 was VCVCV, with a mean average frequency of $29.33 \%$ and $26.0 \%$ for the groups respectively. The most frequently-produced syllable structure in Group 2 was CVCVCV, with a mean average frequency of $22.83 \%$. The following structures featured commonly as the four most frequently-produced structures in all three groups: VCVCV, VCVCVCV, CVCV and CVCVCV. A further perusal of the frequency percentages of these four structures revealed that they were similar across all three age groups, and occurred significantly more frequently than the rest of the structures. The top four structures ranged from $13.66 \%$ to $29.33 \%$, with most structures occurring more frequently than $15.0 \%$ in all three groups. The frequency scores for the rest of the structures were in the $0.16 \%$ to $11.66 \%$ range, with most falling below the $5.0 \%$ level. The most frequently-produced syllable structures consisted of shorter strings of $\mathrm{CV}$ and $\mathrm{VC}$ structures, for example CVCV and VCVCV. As the length of the strings of $C V$ and $V C$ structures increased, the frequency of production decreased. This phenomenon was present in all three age groups, the only exception being the phonotactically-simple VCV and CV structures, which tended to occur further down the order of all three age groups, below a mean average of $5,0 \%$.

\section{Discussion}

\section{Speech sound development in Zulu- speaking children}

The finding of the present study, that single vowel sounds develop before age three, is supported by the findings of the three unpublished studies on Zulu speech sound development (Urquhart, 1967; John, 1988; 
Table 2: The frequency of occurrence (FOO) of Zulu speech sounds, from highest to lowest, in subjects between the ages of 3.0 and 6.2

\begin{tabular}{|c|c|c|c|c|c|}
\hline \multicolumn{2}{|c|}{ 3.0-4.0 (Group 1) } & \multicolumn{2}{|c|}{$4.1-5.1$ (Group 2) } & \multicolumn{2}{|c|}{ 5.2-6.2 (Group 3) } \\
\hline Speech sound & $\mathrm{FOO} \%$ & Speech sound & $\mathrm{FOO} \%$ & Speech sound & $\mathrm{FOO} \%$ \\
\hline a & 19.43 & a & 17.84 & a & 16.97 \\
\hline $\mathrm{i}$ & 13.21 & $\mathrm{i}$ & 12.05 & $\mathrm{i}$ & 13.11 \\
\hline u & 8.06 & u & 7.62 & u & 7.76 \\
\hline 2 & 6.31 & 2 & 6.70 & 2 & 6.47 \\
\hline I & 5.00 & $\mathrm{n}$ & 4.90 & 9 & 4.55 \\
\hline $\mathrm{n}$ & 4.30 & I & 4.65 & s & 4.52 \\
\hline 9 & 4.07 & 9 & 4.35 & I & 4.41 \\
\hline $\mathrm{m}$ & 3.59 & s & 3.74 & $\mathrm{n}$ & 4.11 \\
\hline $\mathrm{s}$ & 3.48 & $\mathrm{~m}$ & 3.30 & j & 3.18 \\
\hline j & 2.74 & $a$ & 3.16 & $\mathrm{~m}$ & 2.82 \\
\hline e & 2.66 & e & 2.65 & e & 2.80 \\
\hline w & 2.54 & j & 2.65 & a & 2.74 \\
\hline $\mathrm{b}$ & 2.40 & $\mathrm{~b}$ & 2.30 & $\mathrm{k} 3$ & 2.14 \\
\hline a & 2.38 & k3 & 2.12 & $\mathrm{~b}$ & 2.11 \\
\hline$t^{\text {h }}$ & 1.73 & o & 2.00 & w & 1.98 \\
\hline $\mathrm{k} 3$ & 1.50 & w & 1.81 & 0 & 1.92 \\
\hline$z$ & 1.41 & $z$ & 1.74 & $t^{h}$ & 1.70 \\
\hline 0 & 1.33 & $\mathrm{k}$ & 1.38 & $\mathrm{k}$ & 1.67 \\
\hline$p^{h}$ & 1.20 & $k^{h}$ & 1.33 & $k^{h}$ & 1.62 \\
\hline $\mathrm{k}$ & 1.13 & $t^{h}$ & 1.33 & $z$ & 1.18 \\
\hline b & 1.05 & $p^{h}$ & 1.09 & $\mathrm{p}^{\mathrm{h}}$ & 1.12 \\
\hline $\mathrm{k}^{\mathrm{h}}$ & 1.02 & $b$ & 1.06 & C & 0.98 \\
\hline : & 0.96 & C & 1.06 & nd & 0.93 \\
\hline C & 0.96 & $\mathrm{~L}$ & 0.90 & $\mathrm{~g}$ & 0.85 \\
\hline$t$ & 0.90 & $f$ & 0.76 & : & 0.82 \\
\hline $\mathrm{L}$ & 0.82 & $t$ & 0.74 & $\mathrm{~L}$ & 0.79 \\
\hline $\mathrm{g}$ & 0.76 & $\mathrm{~g}$ & 0.74 & $f$ & 0.77 \\
\hline nd & 0.65 & nd & 0.50 & b & 0.74 \\
\hline$d$ & 0.62 & adz & 0.50 & $t$ & 0.58 \\
\hline$f$ & 0.60 & : & 0.50 & $\mathrm{M} \mathrm{b}$ & 0.49 \\
\hline & 0.60 & $d$ & 0.48 & $\mathrm{adz}$ & 0.41 \\
\hline ak & 0.60 & $\mathrm{nt}$ & 0.45 & $d$ & 0.38 \\
\hline $\mathrm{adz}$ & 0.45 & v & 0.42 & v & 0.37 \\
\hline 1 & 0.40 & $\mathrm{M} \mathrm{b}$ & 0.35 & $\mathrm{nt}$ & 0.33 \\
\hline adL & 0.37 & $\backslash$ & 0.32 & $p$ & 0.30 \\
\hline $\mathrm{nt}$ & 0.34 & & 0.32 & $\mathrm{dx}$ & 0.30 \\
\hline $\mathrm{M} \mathrm{b}$ & 0.34 & ak & 0.32 & 1 & 0.27 \\
\hline $\mathrm{v}$ & 0.31 & $! g$ & 0.29 & & 0.27 \\
\hline$p$ & 0.25 & $!$ & 0.24 & $\mathrm{~h}$ & 0.19 \\
\hline !g & 0.14 & $\mathrm{~h}$ & 0.21 & $a \backslash$ & 0.19 \\
\hline$a \backslash$ & 0.14 & $p$ & 0.21 & nts & 0.16 \\
\hline $\mathrm{dx}$ & 0.14 & $\mathrm{H}$ & 0.16 & $\mathrm{Mp}$ & 0.16 \\
\hline $\mathrm{H}$ & 0.14 & adL & 0.13 & $!$ & 0.14 \\
\hline 1 & 0.11 & $a \backslash$ & 0.13 & !g & 0.14 \\
\hline$r^{h}$ & 0.11 & $\mathrm{dx}$ & 0.13 & tc & 0.11 \\
\hline $\mathrm{adx}$ & 0.08 & $\mathrm{a!}$ & 0.08 & 1 & 0.11 \\
\hline ! & 0.08 & 1 & 0.08 & $\mathrm{adx}$ & 0.08 \\
\hline nts & 0.06 & $\mathrm{Mp}$ & 0.08 & $r^{h}$ & 0.08 \\
\hline $\mathrm{Mp}$ & 0.06 & $\mathrm{tc}_{\mathrm{c}}$ & 0.08 & g & 0.08 \\
\hline$m \varphi f$ & 0.06 & nts & 0.05 & $\mathrm{H}$ & 0.05 \\
\hline tc & 0.03 & $\mathrm{adx}$ & 0.05 & $\mathrm{adL}$ & 0.05 \\
\hline $\mathrm{h}$ & 0.03 & at: & 0.03 & $M \varphi f$ & 0.03 \\
\hline
\end{tabular}


Table 2: (continued)

3.0-4.0 (Group 1)

4.1-5.1 (Group 2)

5.2-6.2 (Group 3)

Speech sound

FOO \%

Speech sound

FOO \%

Speech sound

FOO \%

rh

g

0.03

0.03

Ig

0.03

a\g

0.03

Table 3: The syllable structures of words produced by Zulu-speaking children between the ages of 3.0 and 6.2

\begin{tabular}{lccc}
\hline Syllable structure & Group 1 & Group 2 & Group 3 \\
& $3.0-4.0$ & $4.1-5.1$ & $5.2-6.2$ \\
\hline VCVCV & + & + & + \\
VCVCVCV & + & + & + \\
CVCV & + & + & + \\
CVCVCV & + & + & + \\
VCVCVCVCV & + & + & + \\
CVCVCVCV & + & + & + \\
VCV & + & + & + \\
CVCVCVCVCV & + & - & + \\
CV & - & - & + \\
CVCVCVCVCVCV & - & - & - \\
VCVCVCVCVCV & - & & - \\
VCVCVCVCVCVCV & - & + & + \\
\hline
\end{tabular}

Plus (+) indicates: syllable structures present in the syllable inventory of the age group Minus (-) indicates: syllable structures absent from the syllable inventory of the age group Abbreviations: $\mathrm{V}=$ vowel; $\mathrm{C}=$ consonant

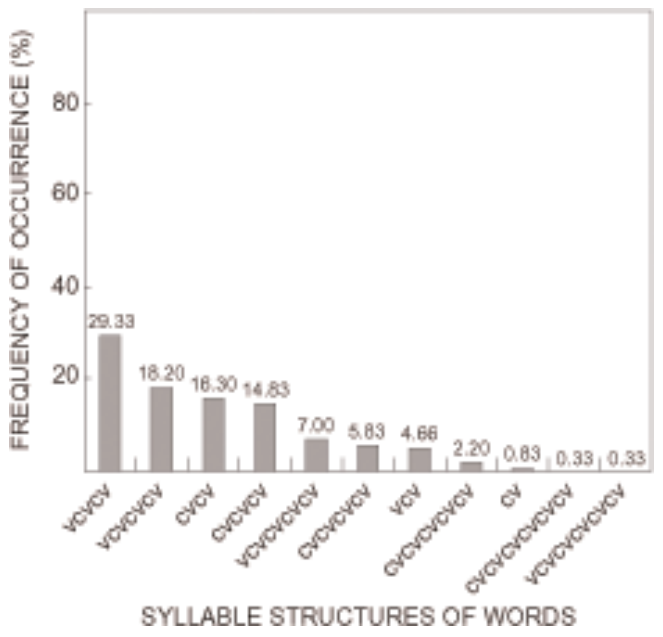

Figure 1: The frequency of occurrence of syllable structures from highest to lowest in subjects between the ages of 3.0 and 4.0 (Group 1)
Kunene, 1999). This finding is also supported by the literature on English speech sound development (Templin, 1957; Irwin \& Wong, 1983; Otomo \& Stoel-Gammon, 1992). Diphthongs do not occur in Zulu and none were recorded during this study.

With regard to the consonant sound inventory of Group 1, Group 2 and Group 3, the results indicate that all three groups produced approximately $50 \%$ of the consonant sounds included in the adult Zulu phonetic inventory. By the age of 6.2 the subjects had mastered $52 \%$ of the required consonant sounds. Between the ages of 3.0 and 6.2 gradual change in terms of the speech sound acquisition occurs in these subjects. The speech sounds that are acquired between the ages of 3.0 and 6.2 are the prenasalised plosive /nt/ and the prenasalised affricate /nts/. This developmental progression clearly indicates that speech sound development is 


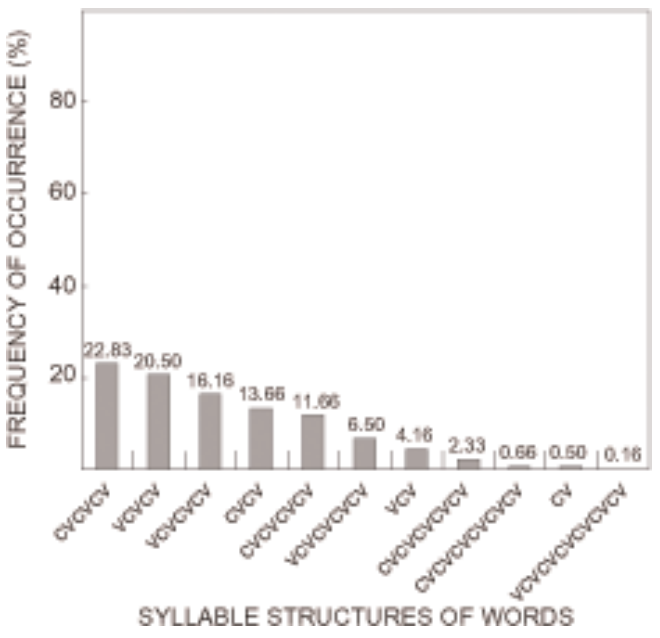

Figure 2: The frequency of occurrence of syllable structures from highest to lowest in subjects between the ages of 4.1 and 5.1 (Group 2)

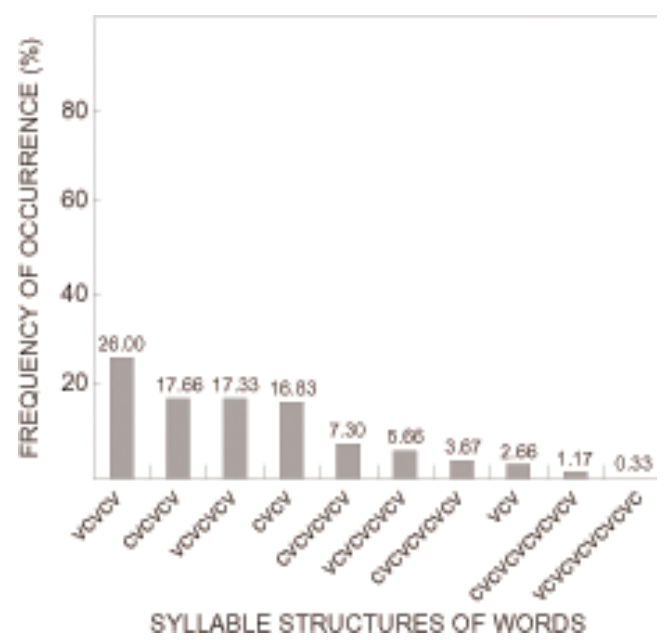

Figure 3: The frequency of occurrence of syllable structures from highest to lowest in subjects between the ages of 5.2 and 6.2 (Group 3)

occurring, and sounds are being integrated into the sound system of the subjects between the ages of 3.0 and 6.2. Further evidence of developmental progression is also noted in the frequency of occurrence of speech sound data of all three groups (see Table 2). It is thus clear that in Zulu children, much speech sound development occurs before the age of three. All the speech sounds present in the 3.0 to 6.2 inventory, aside from /nts, nt/, develop before the age of 3.0.

As reported earlier in the text, there were a few sounds that were present in the inventories of Group 1 and Group 2 but not in Group 3. As speech is developmental in nature, it is highly likely that these sounds had not been produced due to lack of opportunity and not lack of ability. The percentage of acquired sounds is thus likely to be slightly higher than the 52\% indicated above. The criterion of five or more of the subjects producing a sound in order for it to be documented as acquired, was, however, not met. The nature of a spontaneous continuous speech sample is such that the number of opportunities for production of a speech sound cannot be prescribed as in an elicited naming sample, where a sample of every sound can be ensured. The only provision that could be, and was, made was to attempt to gain a large and varied sample, which would allow for many opportunities for the production of each speech sound. The finding of a relatively small consonant sound inventory in all three age groups may have been influenced to some degree by the lack of opportunity for the production of more consonant sounds. Some of the consonant sounds not documented in the inventory of the 3.0 to 6.2 age group may have had too low a frequency of occurrence to have been found in a 100-word speech sample. Given that the complete Zulu consonant inventory of 59 sounds is larger than that of the English inventory of 26 consonant sounds, Grunwell's (1982) guideline of a 100-word speech sample may, in retrospect, have been insufficient in the present study. The strict criterion of five out of six subjects producing the sound for inclusion in the speech sound inventory also limits the inventory. This strict criterion was necessary to support the contention of mastery.

According to the findings on universal speech development by Jakobson (1968), vowel sounds develop earliest, followed consecutively by nasals, glides, stops, fricatives and affricates. Group 1 was able to produce all the possible vowels, nasals, plosives and approximants, which indicates that these sounds develop before the age of three. However, they were not able to produce two of the nine possible fricatives and three of 
the four affricates. These findings support the conclusion of Jakobson (1968) that certain classes develop later.

Studies on speech sound development in American English-speaking children are rarely in agreement. The most stable and oftenquoted data appears to be that of Sanders (1972), which was a reinterpretation of the findings of Templin and Wellman (Sanders, 1972). According to Sanders (1972), /m, n, h, p, w, b, a, k, g, d, t/ are expected to develop before the age of three. This is the case with the subjects of the present study, except for the fricatives $/ \mathrm{h} /$ and $/ \mathrm{H} /$ which are not yet documented as acquired by Groups 1, 2 or 3 . The subjects in Group 1 were also able to produce $\mathrm{k} k 3, \mathrm{p}^{\mathrm{h}} \mathrm{t}^{\mathrm{h}}, \mathrm{k}^{\mathrm{h}}, \mathrm{b}, \mathrm{v}, \mathrm{z}, \mathrm{kx}, \mathrm{f}, \mathrm{s}, ; \mathrm{c}, \mathrm{a}, \mathrm{n}, \mathrm{I}$, $\mathrm{j}, \mathrm{mb}, \mathrm{nd}, \mathrm{adx}, \mathrm{adL}, \mathrm{ak} /$. According to Sanders (1972), additional sounds that are acquired between the ages of 3.0 and 4.0 are /f, j, l, s, r/. Aside from the $/ r /$ which is not part of the Zulu phonetic inventory, the subjects in Group 1 of the present study were able to produce all the above sounds. According to Sanders (1972), children between the ages of four and six acquire the sounds $/ T, D, z, v, c, x, t_{c}, d x /$. In the present study, the fricatives $/ z, v, c /$ are already acquired by Group 1, while the affricates /tc, $\mathrm{dx} /$ are still not documented as acquired by Group 3. The /T, D, $x /$ are not part of the Zulu phonetic inventory. In terms of speech sound type, it is interesting to note that the least-produced classes of sounds in all three age groups are the clicks and prenasalised consonant sounds. This is an expected finding as these sounds require complex articulatory adjustment, and are uncommon in most languages. According to Stockwell and Macaulay (1972), sounds that are rare and require complex articulatory adjustment tend to develop later and are prone to misarticulation.

With regard to the previous findings on Zulu speech sound development, Urquhart (1967) found that the first sounds to develop are nasals, followed by resonants, fricatives and clicks. John (1988) agreed that clicks occur last. According to Kunene (1999), early to develop are stops, liquids, glides, nasals and fricatives, while clicks and affricates develop later. There is agreement between these earlier findings and the present study, in that it is found that plosives, nasals, approximants and fricatives develop early, and that affricates and clicks develop later. However, Kunene (1999) also claims that all sounds were acquired by four years of age, and that the Zulu-speaking three-year olds only had $/ \mathrm{k} /$ to master. This is contrary to the current findings, as described earlier. The difference may lie in the fact that the current study relies on spontaneous conversational speech as opposed to elicited words, which were used in the previous studies. There are significant differences between the present study and the previous studies, in terms of the methodology and definition of terms, and this may account for some of the differences in the findings. It is important to note that the previous studies did not consider the category of prenasalised consonants.

The frequency of vowel sound production is the same across all three age groups. This finding highlights the stability of the data. The high frequency of vowel sound production, as compared to consonant sound production, is an expected finding in a Zulu sample. The syllable structure of the language is vowel-intensive, with no word-final consonants and consonant clusters (Poulos \& Msimang, 1998).

The findings for all three age groups, with regard to the order of frequency of consonant sounds, are similar. In fact, the top five most frequently-produced consonant sounds for Group 1 and Group 3 are the same, although in a different order, namely /l, n, m, s, j/. Group 2 corresponds to the other two groups in terms of the top four positions $/ \mathrm{n}, \mathrm{I}, \mathrm{s}, \mathrm{m} /$, but $/ \mathrm{a} /$ replaced /j/ in the fifth position, and /j/ took sixth position. There is thus agreement across the three age groups on the most frequentlyproduced consonant sounds. Of significance is that a cumulative total of the frequency of the top six consonant sounds in each of the three age groups amounts to more than $20 \%$.

These findings are valuable from a clinical point of view. In clinical assessment, the findings can assist in estimating approximately how well a child's speech sounds are developing, as compared to normal children of his or her age group. The clinical implication of the findings on frequency of speech sound production is that it would be advisable to consider the high frequency consonant sounds as possible targets for treatment, as their impact on intelligibility is greater (Weiss et al., 
1987). Furthermore, according to Hawkins (1995), the more frequently a speech sound occurs in a language, the less motorically complex it is. This again endorses the importance of first selecting, as targets for therapy, those sounds that are produced more frequently by children with normal articulation. Furthermore, in clinical treatment of Zuluspeaking children with articulation problems, developmental apraxia of speech and adults with apraxia of speech, these early- developing speech sounds of normal speakers can be used as targets. A more comprehensive selection of targets can be gleaned by utilising the results of the frequency of speech sound production analysis.

\section{Syllable structure development in Zulu-speaking children}

What emerges from the data is an indication that the shorter word shapes, namely those consisting of one to five syllables, are acquired before the age of 3.0 to 4.0 and are maintained by the older age groups. The only exception is that the structure $\mathrm{CV}$ is not documented as acquired by any of the three age groups. This finding is probably due to the fact that this structure occurs infrequently in the Zulu language (Doke, 1967; Cope, 1983).

Zulu-speaking children appear to be using longer strings of syllables at a younger age than English speakers. According to the findings of Hoffman (1986) and Shriberg (1993), English speakers are not expected to use three or more syllable word shapes by the age of 3.0, as much syllable reduction occurs below the age of 3.0. With the Zulu speakers, much of the syllable development appears to occur before age 3.0, with gradual further development occurring in the 3.0 to 6.2 age range. As Zulu speakers are expected to produce one- to nine- syllable words (Cope, 1983; Poulos \& Bosch, 1997), it is probable that the development of seven- to nine- syllable words occurs after the age of 6.2.

That Zulu-speaking children appear to use longer strings of syllables than Englishspeaking children, at an earlier age, may be explained by the phenomenon that Zulu appears to obey more of the natural rules for preferred syllable structures than English does. For example, all Zulu syllable structures are open, unlike in English, which has both open and closed syllables. Furthermore, natural rules prefer that vowels not be placed next to each other. Lastly, preferred syllable structures avoid consonant clusters in Zulu, but not in English (Stockwell \& Macaulay, 1972). It is thus evident that Zulu words can have a long and yet simple syllable structure, which facilitates ease of production (Cope, 1983; Poulos \& Bosch, 1997). This fact may explain why Zuluspeaking children produce longer structures earlier.

The findings of the present study support the studies on English children, which indicate that the length of syllable structures is developmental in nature; that is, children are able to produce longer and more complex structures as they grow older (Hoffman et al., 1989). The first developing syllable structures in English are CV followed by VC, CVCV reduplicated, CVC, CCV and multi-syllables (Shriberg, 1993). The current study follows a similar pattern of development, in that shorter syllable structures develop first, followed by longer ones. A literature search has produced no studies on the age of development of Zulu syllable structures that would allow comparison to be made.

The findings regarding the frequency of syllable production demonstrate that the top four most frequently-produced syllable structures occur significantly more frequently than the rest of the syllable structures, in all three age groups. These syllable structures (VCVCV, VCVCVCVC, CVCV, CVCVCV) are produced most frequently by the subjects between the ages of 3.0 and 6.2. Generally, as was expected, the longer structures (five and more syllables) occur less frequently than shorter structures, the only exception being the phonotactically-simple VCV, CV which tends to occur infrequently in all three age groups. As indicated previously, not many words in the Zulu language comprise these two structures, and the subjects would thus not have had much opportunity to produce them. As was also expected, the frequency of occurrence of the longer syllable structures increased with age.

As reported in the literature (Stockwell \& Macaulay, 1972), the structures that occurred frequently in the language were acquired earliest. On comparison of the current findings to other studies, only one similarity emerged. Jacobson (1968) indicated that CV develops 
first, followed by CVCV (reduplicated), then CVC and CVCV (differentiated). Weiss et al. (1987) found that the most frequently-produced syllable structure is CV, followed by VC, CVC and CVCV consecutively. The only commonality between the English findings and the findings in the present study is that CVCV is a structure with a high frequency of occurrence in both. In the current study, the frequency of VC in all three age groups was low, and CVC does not occur in Zulu. There are no other studies on the frequency of syllable structures used by Zulu-speaking children, so no comparisons could be made.

The finding with regard to the most frequently-produced syllable structure has important clinical implications in treating children with articulation disorders, developmental apraxia of speech as well as adults with motor speech disorders. Knowing which syllable structures are produced by normal Zulu-speaking children offers indications for a treatment plan, which proceeds from less complex to more complex. Generally, in treating English subjects, targets would progress from isolated sounds to $\mathrm{CV}$ or VC words to CVC and so on. Using this format would be unsuitable for the Zulu speaker. According to the present study, CVCV occurs frequently in Zulu-speaking children between the ages of 3.0 and 6.2 and it would therefore be appropriate to start with this syllable structure and proceed to duplications of the $\mathrm{CV}$ structure, for example CVCVCV.

\section{Conclusions and recommendations}

The present study was useful in providing the groundwork or offering guidelines when embarking on studies of this nature. It may focus attention on the dire need for research into the norms of speech development in Zulu. It must, however, be mentioned that the present study would have required a larger subject population, a broadening of the upper and lower age limits as well as an increase in the required speech sample size, in order for the findings to be generalised to the larger population. Intensive normative research is vital in providing the foundation for all further research in speech and language, as well as in developing language and culturally-appropriate assessment and treatment material. The present study was small and limited by practical and financial factors. The information obtained was, however, important and necessary and represented a basic step in the process of developing a comprehensive Zulu speech database. Clearly, additional studies are needed to bring our knowledge of Zulu articulation in children in line with the information we have on English-speaking children, and to further enhance our knowledge base.

Future research using the same methodology and consonant chart, but based on elicited words, to verify the acquisition data, is recommended. As mentioned previously, firm conclusions regarding the age of acquisition could not be made, as the subjects may have been able to produce a specific sound but may not have had the opportunity to do so. Future research could also utilise the same methodology on different sample groups or different language groups, to compare the findings. Replication of the study to check the stability of the results could also be embarked upon. Furthermore, reporting the data in terms of word position, which exerts an important influence on production, would also be useful, and is an important aspect to include in future

\section{References}

Abercrombie D. 1967. Elements of General Phonetics. Edinburgh: Edinburgh University Press.

Allen GD. 1988. The PHONASCII system. Journal of the International Phonetics Association 18(1): 9-25.

Ball MJ \& Rahilly J. 1999. Phonetics: the Science of Speech. Great Britain: Arnold.

Bernhardt BH \& Stemberger JP. 1998. Handbook of Phonological Development from the Perspective of Constraint-based Nonlinear Phonology. San Diego: Academic Press.

Burton MW \& Blumstein SE. 1992. A phonetic analysis of prenasalised stops in Moru. Journal of Phonetics 20: 127-142. 
Cope AT. 1983. A Comprehensive Course in the Zulu Language (revised edn). Department of African Studies textbook. Durban: University of Natal.

Costello J (ed). 1984. Speech Disorders in Children. San Diego: College-Hill Press.

Crary MA. 1993. Developmental Motor Speech Disorders. San Diego: Singular Publishing Group Inc.

Creaghead NA, Newman PW \& Secord WA. 1989. Assessment and Remediation of Articulatory and Phonological Disorders. USA: Merrill Publishing Company.

De Vos AS (ed). 1998. Research at Grass Roots: a Primer for the Caring Professions. Pretoria: Van Schaik Publishers.

Doke CM. 1967. The Southern Bantu Languages. London: Dawsons.

Fundudis T, Kalvin I \& Garside RF. 1979. Speech Retarded and Deaf Children: their Psychological Development. London: Academic Press.

Groenewald E \& Musto C. 1999. Computerised analysis of the sound structure of a language. Clinica: Application in Clinical Practice of Communication Pathology, Monograph 4. Pretoria: University of Pretoria. pp 21-30.

Grunwell P. 1982. Clinical Phonology. London: Croom Helm.

Hawkins P. 1995. Introducing Phonology. London: Routledge.

Hoffman KA. 1986. Speech sound acquisition and natural process occurrence in the continuous speech of three-to-six year old children. In: Shriberg LD (ed) PEPPER: Programs to Examine Phonetic and Phonological Evaluation Records. New Jersey: Lawrence Erlbaum.

Hoffman PR, Schuckers GH \& Daniloff RG. 1989. Childrens Phonetic Disorders: Theory and Treatment. Boston: College-Hill Press.

Irwin JV \& Wong SP. 1983. Phonological Development in Children: 18 to 72 Months. Illinois: Southern Illinois University Press.

Jakobson R. 1968. Child Language, Aphasia and Phonological Universals. The Hague: Mouton.

John Y. 1988. An investigation of the phonological processes in Zulu preschool children as a function of age. Unpubl. Bachelor of Speech and Hearing Therapy research report, University of Durban-
Westville.

Kunene X. 1999. A developmental profile of speech (consonantal phonemes) development in Zulu-speaking children between the ages of three to five years. Unpubl. Bachelor of Speech and Hearing Therapy research report, University of Durban-Westville.

Lanham LW. 1960. The Comparative Phonology of Nguni. Department of African Studies textbook. Grahamstown: Rhodes University.

Leedy PD. 1997. Practical Research Planning and Design. New Jersey: Prentice Hall Inc.

Lephallo AT. 1990. A Comparative Study of the Influence of the Nasal Prefix $/ \mathrm{n} /$ (from urbantu ' $n i$ ') on Succeeding Consonants at the Beginning of Some Lexical Items in Zulu, Xhosa and Southern Sotho. MA dissertation, University of Zululand.

Levelt CC, Schiller NO \& Levelt JM. 1999. A developmental grammar for syllable structure in the production of child language. Brain and Language 68: 291-299.

McWilliams BJ, Morns HL \& Shelton RL. 1984. Cleft Palate Speech. Philadelphia: BC Decker Inc.

Morrison JA \& Shriberg LD. 1992. Articulation testing versus conversational speech sampling. Journal of Speech and Hearing Research 35: 259-273.

Mouton J \& Marais HC. 1990. Basic Concepts in the Methodology of the Social Sciences. Pretoria: HSRC.

Naidoo Y. 2003. A Developmental Profile of Speech Sound and Syllable Acquisition in Zulu-speaking Children. Masters in Communication Pathology thesis, University of Pretoria.

Otomo K \& Stoel-Gammon C. 1992. The acquisition of unrounded vowels in English. Journal of Speech and Hearing Research 35: 604-616.

Poulos G \& Bosch SE. 1997. Zulu. Munchen: Lincom-Europa.

Poulos G \& Msimang CT. 1998. A Linguistic Analysis of Zulu. Cape Town: Via Africa.

Rennison J \& Suzman S. 2000. Computer coding of Zulu. Unpublished paper, $2^{\text {nd }}$ International Symposium

on Communication Disorders in Multilingual 
Populations, Kwa Maritane, South Africa.

Sanders E. 1972. When are speech sounds learned? Journal of Speech and Hearing Disorders 37: 55-63.

Shriberg LD. 1993. Four new speech and prodosy-voice measures for genetic research and other studies in developmental phonological disorders. Journal of Speech and Hearing Research 36: 105-140.

Shriberg LD \& Lof GL. 1991. Reliability studies in broad and narrow phonetic transcription. Clinical Linguistics and Phonetics 5: 225-279.

Shriberg LD \& Widder CJ. 1990. Speech and prosody characteristics of adults with mental retardation. Journal of Speech and Hearing Research 33: 627-653.

Smit AB. 1986. Ages of speech sound acquisition: comparisons and critiques of several normative studies. Language, Speech \& Hearing Services in Schools 17: 175-186.

Statistics South Africa. 2000. Statistics in Brief 2000. Pretoria: Statistics South Africa.

Stockwell RP \& Macaulay RKS. 1972. Linguistic Change and Generative Theory. USA: Indiana University Press.

Taljaard PC \& Snyman JW. 1993. An Introduction to Zulu Phonetics. Cape Town: Marius Lubbe Publishers.

Templin MC. 1957. Certain Language Skills in Children: their Development and Interrelationship. Minneapolis: University of Minnesota Press.
Urquhart C. 1967. A study demonstrating the competency of articulation at various age levels in the Zulu child. Unpublished Bachelor of Logepaedics research report, University of the Witwatersrand.

Van Rooy B \& Grijzenhout J. 2000. Voicing phenomena in Zulu-English. Unpublished paper, International Conference on Linguistics in Southern Africa. Cape Town, South Africa.

Vihman MM. 1993. Variable paths to early word production. Journal of Phonetics 21: 61-82.

Vihman MM. 1996. Phonological Development: the Origins of Language in the Child. Cambridge: Blackwell Publishers Inc.

Weiss CE, Gordon ME \& Lillywhite HS. 1987. Clinical Management of Articulatory and Phonological Disorders. New Jersey: Prentice Hall Inc.

Westerman D \& Ward IC. 1990. Practical Phonetics for Students of African Languages. Great Britain: TJ Press.

Ziervogel D (ed). 1967. Handbook of the Speech Sounds and Sound Changes of the Bantu Languages of South Africa. Pretoria: UNISA. 
Appendix A: Zulu consonant chart

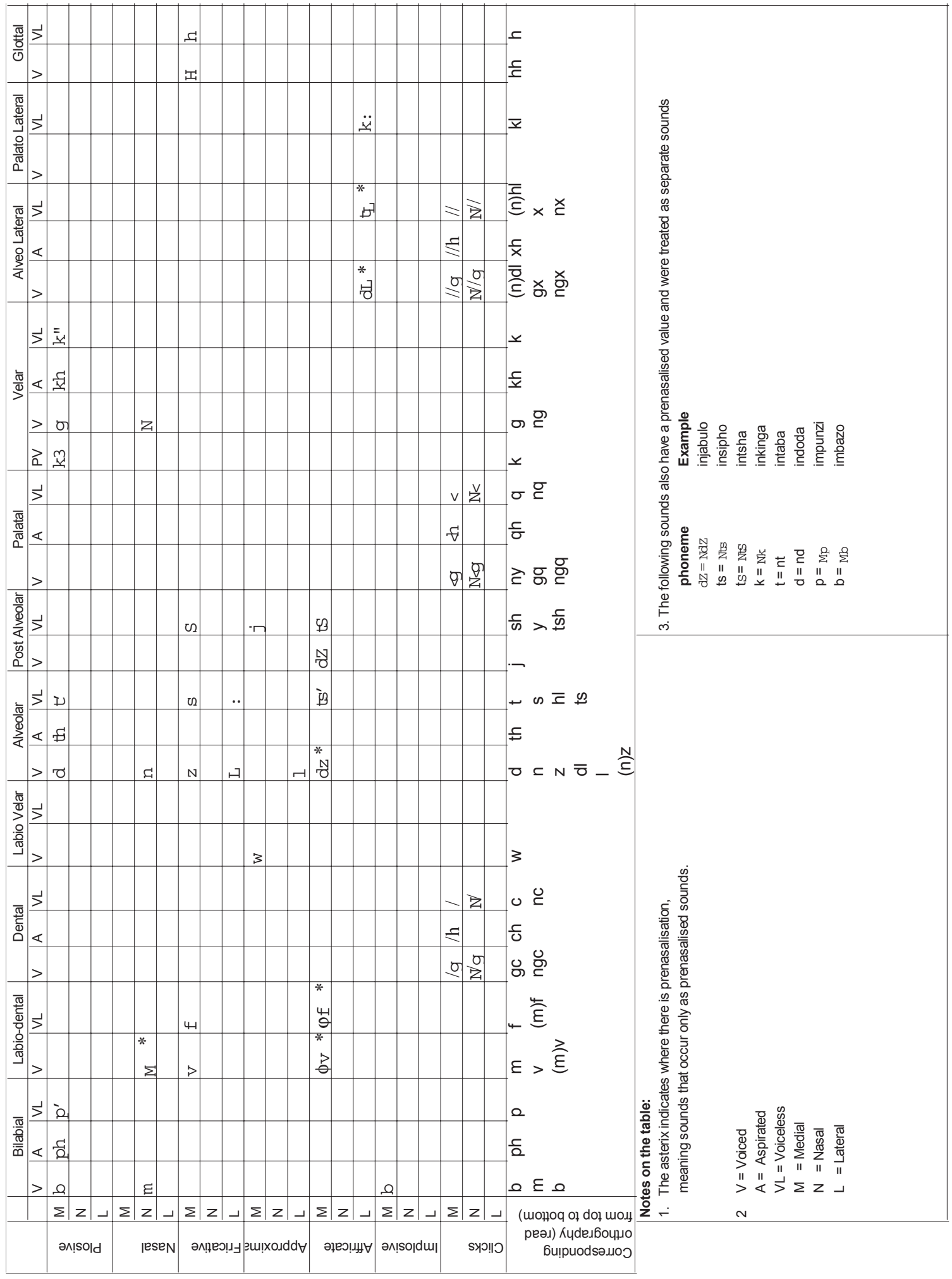

